\title{
Pengaruh Sistem Hidroponik dan Media Tanam Terhadap Pertumbuhan dan Produksi Tanaman Sawi (Brassica rapa L)
}

\section{Effect of Hydroponic Systems and Planting Media on Growth and Production of mustard greens Plants (Brassica rapa L)}

\author{
Nur Hafijah ${ }^{1}$, Tutik Nugrahini ${ }^{2}$, Zainudin ${ }^{2}$ \\ 1 Alumni Program Studi Agroteknologi, Fakultas Pertanian, Universitas Widya Gama Mahakam Jl. KH. Wahid \\ Hasyim, Sempaja, Samarinda, Kalimantan Timur, Indonesia \\ 2 Tenaga Pendidik Program Studi Agroteknologi, Fakultas Pertanian, Universitas Widya Gama Mahakam Jl. KH. \\ Wahid Hasyim, Sempaja, Samarinda, Kalimantan Timur, Indonesia
}

Email : hafijahnur@gmail.com, tutik.nugrahini@gmail.com,ztjimpolo@gmail.com

Diterima : 4 April 2019 Disetujui : 17 Juni 2019

\begin{abstract}
Effect of hydroponic systems and planting media on growth and production of mustard plants (Brassica rapa L) The purpose of this study was to determine the effect of systems and different hiodroponic growing media on the growth and production of mustard plants. This research was conducted for 3 months, starting from June to September 2017. The research location was located in Embalut village, Tenggarong Sub-District, across the Kutai Kartanegara Regency, East Kalimantan Province. The research design used was Completely Randomized Design (CRD) consisting of 2 factors with 5 replications, the first factor was the hydroponic system consisting of 3 (three) levels, namely: system wick $\left(s_{1}\right)$, system NFT $\left(s_{2}\right)$, system DFT $\left(s_{3}\right)$. The second factor is $m_{1}=$ husk charcoal, $m_{2}=$ Cocopeat, $m_{3}=$ Rockwool. The results of this study indicate that the treatment system has a very significant effect on the average number of leaves, leaf width, plant height, leaf width of mustard plants aged 4, 5 and $6 \mathrm{mst}$, did not significantly affect the fresh weight of mustard plants. The media treatment did not affect the average number of leaves, plant height, leaf width of plants at 4, 5, 6 and fresh weight of plants did not have significant effect. The effect of the best system treatment on the growth of mustard plants produced by the NFT system $\left(s_{2}\right)$, the best media treatment for the growth of mustard plants was produced by the Cocopeat treatment $\left(m_{2}\right)$. The highest interaction with the fresh weight of mustard plants was produced by a combination of treatment $s_{2} x m_{2}$; ;
\end{abstract}

Keywords: Hydroponic systems, planting media and mustard greens

\section{PENDAHULUAN}

Hidroponik merupakan salah satu alternatif pertanian yang modern seperti saat ini yang sudah berkembang dikalangan masyarakat. Baik itu di pedesaan maupun di perkotaan yang memiliki lahan sempit. Sistem budidaya ini memungkinkan bercocok tanam tanpa menggunakan tanah dan juga dapat dilakukan di dalam ruangan (indoor) (Eselon, 2014).

Hidroponik diperkirakan pada awal tahun 1980-an masuk ke Indonesia, dan saat itu hanya para penggemar/hobi saja yang tertarik dan mengembangkan model budidaya hidroponik. Namun dalam perjalanan waktu, tidak hanya sebagai sarana penyaluran hobi. Metode bertanam tanpa tanah ini berkembang seiring dengan berjalannya waktu, dan saat ini dikenal berbagai jenis hidroponik, antara lain: Nutrien Film Technique (NTF), Wick System,
Floating System, Ebb and Flow, Drip Irrigation, Aeroponik, dll (Eselon, 2014).

Tanaman hidroponik adalah tanaman yang ramah lingkungan. Budidaya tanaman menggunakan sistem hidroponik ini memiliki banyak keunggulan bila dibandingkan dengan metode tanaman yang lain. banyak para petani yang kini beralih ke sistem hidroponik. Karena hasil yang didapatkan dari menanam hidroponik jauh lebih meningkat dibanding metode lainnya (Eselon, 2014).

Pengembangan budidaya sawi hidroponik mempunyai prospek baik untuk mendukung upaya peningkatan pendapatan petani, gizi masyarakat, perluasan kesempatan kerja. Peningkatan pendapatan Negara melalui pengurangan impor dan memacu laju pertumbuhan ekspor. Kelayakan pengembangan budidaya sawi antara lain ditujukan oleh adanya keunggulan komparatif kondisi wilayah tropis Indonesia yang sangat 
cocok untuk komoditas tersebut. Umur panen sawi relative pendek dan hasilnya memberikan keuntungan yang memadai. (Arinong,, 2008).

Berdasarkan uraian diatas maka dianggap perlu melakukan penelitian tentang "Pengaruh Sistem Hidroponik dan Media Tanam Terhadap Pertumbuhan dan Produksi Tanaman Sawi (Brassica rapa L).

\section{BAHAN DAN METODE}

Penelitian ini dilaksanakan selama 3 (tiga) bulan, terhitung mulai bulan Juni 2017 sampai dengan September 2017. Lokasi penelitian terletak di Desa Embalut Kecamatan Tenggarong Seberang Kabupaten Kutai Kartanegara Provinsi Kalimantan Timur. Bahan yang digunakan dalam penelitian ini adalah : Benih sawi jenis pakcoy, nutrisi A dan B Ijo, Air, arang sekam, cocopeat, rockwool. Penelitian ini disusun dalam Rancangan Acak Lengkap (RAL) dengan analisis fatorial $3 \times 3$ dan diulang sebanyak 5 (lima) kali ulangan. Perlakuan terdiri dari 2 (dua) faktor, yaitu : Faktor pertama adalah system hidroponik (S) yang berbeda terdiri dari 3 (tiga) taraf,yaitu $: \mathrm{s}_{1}$ : wick system, $\mathrm{s}_{2}$ : nft system dan $\mathrm{s}_{3}$ : dft system dan faktor kedua adalah media tanam (M) yang berbeda terdiri dari 3 (tiga) taraf,yaitu : $\mathrm{m}_{1} \quad$ : arang sekam, $\mathrm{m}_{2}$ cocopeat dan $\mathrm{m}_{3} \quad$ : rockwool. Model linier untuk percobaan ini adalah

$$
Y_{i j k} \quad=\mu+\alpha i+\beta_{j}+(\alpha \beta)_{i j}+\varepsilon_{i j k}
$$

$\mathrm{Y}_{\mathrm{ijk}}=$ Nilai Pengamatan faktor Nutrisi taraf ke-i faktor Sumbu taraf ke- j dan ulangan ke-k

$\mu \quad=$ Rataan umum

$\alpha \mathrm{i}=$ Pengaruh aditif dari faktor sistem taraf ke-i $(i=1,2,3,4$,

$\beta_{\mathrm{j}}=$ Pengaruh aditif dari faktor media taraf ke-j $(j=1,2,3,4)$

$(\alpha \beta)_{\mathrm{ij}}=$ Komponen interaksi dari faktor sistem dan faktor media

$\varepsilon_{\mathrm{ijk}}=$ Galat pada faktor sistem dan faktor media pada ulangan ke- $\mathrm{k}$

Pelaksanaan penelitian meliputi : persiapan benih, penyemaian, persiapan media tanam, pembuatan larutan nutrisi, penanaman, pemeliharaan. Variabel yang diamati ; jumlah daun, jumlah daun, tinggi tanaman, lebar daun dan berat segar pertanaman. Data hasil pengamatan dan pengukuran ditabulasi kemudian dianalisis secara statistik menggunakan sidik ragam (Anova), Jika berbeda nyata hasil analisis sidik ragam dilanjutkan dengan uji Duncan's Multiple Range Test (DMRT) dengan taraf 5\%.

\section{HASIL DAN PEMBAHASAN}

Tabel 1. Rata-rata Jumlah Daun Tanaman Sawi (helai) Umur 4 MST Dengan Pengaruh Sistem dan Media Tanam

\begin{tabular}{ccccc}
\hline \multirow{2}{*}{ Sistem } & \multicolumn{3}{c}{ Media } & \multirow{2}{*}{ Rata-rata } \\
\cline { 2 - 4 } & $\mathrm{m}_{1}$ & $\mathrm{~m}_{2}$ & $\mathrm{~m}_{3}$ & $6,96 \mathrm{~b}$ \\
$\mathrm{~s}_{1}$ & 6,80 & 6,60 & 7,50 & $7,20 \mathrm{a}$ \\
$\mathrm{s}_{2}$ & 6,70 & 7,30 & 7,60 & $7,70 \mathrm{a}$ \\
$\mathrm{s}_{3}$ & 7,80 & 7,50 & 7,80 & \\
Rata-rata & $7,10 \mathrm{a}$ & $7,13 \mathrm{a}$ & $7,63 \mathrm{a}$ &
\end{tabular}

Keterangan : Angka-angka dengan yang di ikuti huruf yang sama menunjukan tidak berbeda nyata pada uji DMRT $5 \%($ DMRT $\mathrm{s}=1,90, .2,00$ dan DMRTm $=1,90, .2,00)$

Tabel 2. Rata-rata Jumlah Daun Tanaman Sawi (helai) Umur 5 MST Dengan Pengaruh Sistem dan Media Tanam

\begin{tabular}{ccccc}
\hline \multirow{2}{*}{ Sistem } & \multicolumn{3}{c}{ Media } & Rata-rata \\
\cline { 2 - 4 } & $\mathrm{m}_{1}$ & $\mathrm{~m}_{2}$ & $\mathrm{~m}_{3}$ & $9,23 \mathrm{~b}$ \\
& 9,50 & 8,50 & 9,70 & $10,13 \mathrm{a}$ \\
$\mathrm{s}_{1}$ & 9,80 & 10,20 & 10,40 & $10,46 \mathrm{a}$ \\
$\mathrm{s}_{2}$ & 10,70 & 9,70 & 11,00 & \\
$\mathrm{~s}_{3}$ & $10,00 \mathrm{a}$ & $9,46 \mathrm{a}$ & $10,36 \mathrm{a}$
\end{tabular}

Rata-rata $\quad 10,00$ a $\quad 9,46$ a 10,36 a

Keterangan : Angka-angka dengan yang di ikuti huruf yang sama menunjukan tidak berbeda nyata pada uji DMRT $5 \%($ DMRT $\mathrm{s}=1,90, .2,00$ dan DMRTm $=1,90, .2,00)$ 
Tabel 3. Rata-rata Jumlah Daun Tanaman Sawi (helai) Umur 6 MST Dengan Pengaruh Sistem dan Media Tanam

\begin{tabular}{ccccc}
\hline \multirow{2}{*}{ Sistem } & \multicolumn{3}{c}{ Media } & \multirow{2}{*}{ Rata-rata } \\
\cline { 2 - 4 } & $\mathrm{m}_{1}$ & $\mathrm{~m}_{2}$ & $\mathrm{~m}_{3}$ & \\
\hline $\mathrm{s}_{1}$ & 11,50 & 10,40 & 12,30 & $11,40 \mathrm{~b}$ \\
$\mathrm{~s}_{2}$ & 13,10 & 13,60 & 13,50 & $13,40 \mathrm{a}$ \\
$\mathrm{s}_{3}$ & 13,50 & 12,80 & 14,50 & $13,60 \mathrm{a}$ \\
\hline Rata-rata & $12,70 \mathrm{a}$ & $12,26 \mathrm{a}$ & $13,43 \mathrm{a}$ & \\
\hline
\end{tabular}

Keterangan : Angka-angka dengan yang di ikuti huruf yang sama menunjukan tidak berbeda nyata pada uji DMRT 5\% (DMRT $\mathrm{s}=1,90, .2,00$ dan DMRTm $=1,90, .2,00$ )

Tabel 4. Rata-rata Lebar Daun Sawi (cm) Umur 4 MST Dengan Pengaruh Sistem dan Media Tanam

\begin{tabular}{ccccc}
\hline \multirow{2}{*}{ Sistem } & \multicolumn{3}{c}{ Media } & \multirow{2}{*}{ Rata-rata } \\
\cline { 2 - 4 } & $\mathrm{m}_{1}$ & $\mathrm{~m}_{2}$ & $\mathrm{~m}_{3}$ & \\
\hline $\mathrm{s}_{1}$ & 4,15 & 4,21 & 4,59 & $4,31 \mathrm{~b}$ \\
$\mathrm{~s}_{2}$ & 5,27 & 5,13 & 4,95 & $5,11 \mathrm{a}$ \\
$\mathrm{s}_{3}$ & 4,80 & 5,08 & 5,14 & $5,06 \mathrm{a}$ \\
\hline Rata-rata & $4,74 \mathrm{a}$ & $5,04 \mathrm{a}$ & $4,89 \mathrm{a}$ & \\
\hline
\end{tabular}

Keterangan : Angka-angka dengan yang di ikuti huruf yang sama menunjukan tidak berbeda nyata pada uji DMRT 5\% (DMRT $\mathrm{s}=1,90, .2,00$ dan DMRTm $=1,90, .2,00)$

Tabel 5. Rata-rata Lebar Daun Sawi (cm) Umur 5 MST Dengan Pengaruh Sistem dan Media Tanam

\begin{tabular}{ccccc}
\hline \multirow{2}{*}{ Sistem } & \multicolumn{3}{c}{ Media } & \multirow{2}{*}{ Rata-rata } \\
\cline { 2 - 4 } & $\mathrm{m}_{1}$ & $\mathrm{~m}_{2}$ & $\mathrm{~m}_{3}$ & \\
\hline $\mathrm{s}_{1}$ & 4,30 & 4,27 & 4,42 & $4,33 \mathrm{~b}$ \\
$\mathrm{~s}_{2}$ & 5,65 & 5,43 & 5,03 & $5,46 \mathrm{a}$ \\
$\mathrm{s}_{3}$ & 4,92 & 5,20 & 5,34 & $5,15 \mathrm{a}$ \\
\hline Rata-rata & $4,95 \mathrm{a}$ & $4,96 \mathrm{a}$ & $5,02 \mathrm{a}$ &
\end{tabular}

Keterangan : Angka-angka dengan yang di ikuti huruf yang sama menunjukan tidak berbeda nyata pada uji DMRT 5\% (DMRT s= 1,90,. 2,00 dan DMRTm $=1,90, .2,00$ )

Tabel 6. Rata-rata Lebar Daun Sawi (cm) Umur 6 MST Dengan Pengaruh Sistem dan Media Tanam

\begin{tabular}{ccccc}
\hline \multirow{2}{*}{ Sistem } & \multicolumn{3}{c}{ Media } & \multirow{2}{*}{ Rata-rata } \\
\cline { 2 - 4 } & $\mathrm{m}_{1}$ & $\mathrm{~m}_{2}$ & $\mathrm{~m}_{3}$ & $4,64 \mathrm{~b}$ \\
$\mathrm{~s}_{1}$ & 4,78 & 4,31 & 4,85 & $5,44 \mathrm{a}$ \\
$\mathrm{s}_{2}$ & 5,73 & 5,49 & 5,10 & $5,25 \mathrm{a}$ \\
$\mathrm{s}_{3}$ & 5,05 & 5,24 & 5,46 &
\end{tabular}

Keterangan : Angka-angka dengan yang di ikuti huruf yang sama menunjukan tidak berbeda nyata pada uji DMRT 5\% (DMRT s= 1,90,. 2,00 dan DMRTm $=1,90, .2,00$ )

Tabel 7. Rata-rata tinggi tanaman Sawi (cm) Umur 4 MST Dengan Pengaruh Sistem dan Media Tanam

\begin{tabular}{ccccc}
\hline \multirow{2}{*}{ Sistem } & \multicolumn{3}{c}{ Media } & \multirow{2}{*}{ Rata-rata } \\
\cline { 2 - 4 } & $\mathrm{m}_{1}$ & $\mathrm{~m}_{2}$ & $\mathrm{~m}_{3}$ & \\
\hline $\mathrm{s}_{1}$ & 9,16 & 9,48 & 9,70 & $9,44 \mathrm{~b}$ \\
$\mathrm{~s}_{2}$ & 11,09 & 11,33 & 10,18 & $10,86 \mathrm{a}$ \\
$\mathrm{s}_{3}$ & 10,08 & 9,97 & 10,27 & $10,10 \mathrm{a}$ \\
\hline Rata-rata & $10,11 \mathrm{a}$ & $10,26 \mathrm{a}$ & $10,05 \mathrm{a}$ & \\
\hline
\end{tabular}

Keterangan : Angka-angka dengan yang di ikuti huruf yang sama menunjukan tidak berbeda nyata pada uji DMRT 5\% (DMRT s=1,90,. 2,00 dan DMRTm = 1,90,. 2,00) 
Tabel 8. Rata-rata tinggi tanaman Sawi (cm) Umur 5 MST Dengan Pengaruh Sistem dan Media Tanam

\begin{tabular}{ccccc}
\hline \multirow{2}{*}{ Sistem } & \multicolumn{3}{c}{ Media } & \multirow{2}{*}{ Rata-rata } \\
\cline { 2 - 4 } & $\mathrm{m}_{1}$ & $\mathrm{~m}_{2}$ & $\mathrm{~m}_{3}$ & $9,45 \mathrm{~b}$ \\
$\mathrm{~s}_{1}$ & 9,63 & 8,84 & 9,89 & $11,32 \mathrm{a}$ \\
$\mathrm{s}_{2}$ & 11,60 & 11,83 & 10,55 & $10,68 \mathrm{ab}$ \\
$\mathrm{s}_{3}$ & 10,37 & 10,84 & 10,83 & \\
Rata-rata & $10,53 \mathrm{a}$ & $10,50 \mathrm{a}$ & $10,42 \mathrm{a}$ & \\
\hline
\end{tabular}

Keterangan : Angka-angka dengan yang di ikuti huruf yang sama menunjukan tidak berbeda nyata pada uji DMRT 5\% (DMRT s= 1,90,. 2,00 dan DMRTm $=1,90, .2,00)$

Tabel 9. Rata-rata tinggi tanaman Sawi (cm) Umur 6 MST Dengan Pengaruh Sistem dan Media Tanam

\begin{tabular}{ccccc}
\hline \multirow{2}{*}{ Sistem } & \multicolumn{3}{c}{ Media } & \multirow{2}{*}{ Rata-rata } \\
\cline { 2 - 4 } & $\mathrm{m}_{1}$ & $\mathrm{~m}_{2}$ & $\mathrm{~m}_{3}$ & $9,67 \mathrm{~b}$ \\
$\mathrm{~s}_{1}$ & 10,03 & 8,97 & 10,03 & $11,43 \mathrm{a}$ \\
$\mathrm{s}_{2}$ & 11,68 & 11,95 & 10,68 & $10,78 \mathrm{ab}$ \\
$\mathrm{s}_{3}$ & 10,55 & 10,78 & 11,03 & \\
\hline Rata-rata & $10,75 \mathrm{a}$ & $10,56 \mathrm{a}$ & $10,58 \mathrm{a}$ & \\
\hline
\end{tabular}

Keterangan : Angka-angka dengan yang di ikuti huruf yang sama menunjukan tidak berbeda nyata pada uji DMRT 5\% (DMRT $\mathrm{s}=1,90, .2,00$ dan DMRTm $=1,90, .2,00$ )

Tabel 10. Rata-rata berat segar tanaman sawi (gram) Umur 6 MST Dengan Pengaruh Sistem dan Media Tanam

\begin{tabular}{ccccc}
\hline \multirow{2}{*}{ Sistem } & \multicolumn{3}{c}{ Media } & \multirow{2}{*}{ Rata-rata } \\
\cline { 2 - 4 } & $\mathrm{m}_{1}$ & $\mathrm{~m}_{2}$ & $\mathrm{~m}_{3}$ & $10,73 \mathrm{~b}$ \\
$\mathrm{~s}_{1}$ & 11,26 & 10,34 & 10,13 & $12,83 \mathrm{a}$ \\
$\mathrm{s}_{2}$ & 13,55 & 13,68 & 11,28 & $11,96 \mathrm{ab}$ \\
$\mathrm{s}_{3}$ & 12,09 & 11,45 & 12,36 & \\
\hline Rata-rata & $12,30 \mathrm{a}$ & $11,82 \mathrm{a}$ & $11,25 \mathrm{a}$ & \\
\hline
\end{tabular}

Keterangan : Angka-angka dengan yang di ikuti huruf yang sama menunjukan tidak berbeda nyata pada uji DMRT 5\% (DMRT s= 1,90,. 2,00 dan DMRTm $=1,90, .2,00$ )

\section{Pengaruh Sistem Hidroponik}

Hasil analisis sidik ragam menunjukan bahwa sistem NFT berpengaruh sangat nyata pada jumlah daun, lebar daun, tinggi tanaman dan berat tanaman umur 4, 5, maupun 6, Keuntungan NFT tidak terjadi kehilangan hara dari pupuk, efisiensi distribusi air tinggi, hanya daerah perakaran yang terbasahi, suplai air dapat diatur dengan baik dan pemupukan dapat dilakukan bersamaan dengan irigasi. NFT merupakan sistem yang paling efisien karena air diberikan dengan debit yang kecil disekitar tanaman. Pada sistem tersebut, kehilangan air dari sumber sampai lahan tidak ada sehingga efisiensi NFT dapat mencapai $90 \%$ dampai 95\% (Haman dan Yeger, 2004), hal ini sesuai dengan penelitian yang dilakukan menunjukan hasil terbaik dengan sistem NFT lebih efektif. Menurut Karsono (2013), bahwa dengan sistem drip irigasi tanaman mendapat suplai air, oksigen, dan nutrisi secara periodik, suplai oksigen lebih baik karena terbawa air pasang surut, mempermudah perawatan karena tidak perlu melakukan penyiraman. Soeseno (1985), dengan sistem wick berpengaruh pada pertumbuhan tanaman karena tidak ada bagianbagian yang bergerak. Dalam hidroponik hal yang perlu diperhatikan adalah larutan nutrisi. Larutan nutrisi merupakan sumber pasokan makanan.

\section{Pengaruh Media Tanam}

Hasil analisis sidik ragam menunjukan bahwa pengaruh media tanam cocopeat 
berpengaruh sangat nyata pada lebar daun umur 4 mst. Menurut Prihmatoro dan Indriani (2003), media tanam sangat penting diperhatikan dalam mendukung pertumbuhan tanaman. Media yang baik yaitu dapat memasok sebagian unsur-unsur hara yang dibutuhkan oleh tanaman. Sebagian besar unsur hara yang dibutuhkan tanaman dipasok melalui media tanam. Selanjutnya diserap oleh perakaran dan digunakan untuk proses fisiologi tanaman. Tiap jenis media tanam mempunyai bobot dan porositas yang berbeda. Dalam memilih media sebaiknya dicari kombinasi media tanam yang tepat sesuai dengan jenis tanaman. Menurut Ihsan (2013), kandungan hara yang terkandung dalam cocopeat yaitu unsur hara makro dan mikro yang dibutuhkan tanaman diantaranya adalah kalium, fosfor, kalium,madnesium dan natrium. Cocopeat dapat menahan kandungan air dan unsur kimia pupuk serta menetralkan kemasaman tanah. Menurut Prihmantoro dan Indriani (2003), cocopeat dapat menyerap air dan dapat menyimpan kandungan air dengan baik (nutrisi) sehingga dapat menjaga ketersediaan nutrisi untuk tanaman ketersediaan oksigen bagi akar sehingga dapat meningkatkan hasil pada tanaman. Ditambahkan Ihsan (2013), dapat menahan kandungan air dan unsur kimia pupuk serta dapat menetralkan keasaman tanah dan kandungan fosfor $(\mathrm{P})$ dan kalium (K). Seperti yang telah kita ketahui bahwa kandungan Fosfor $(\mathrm{P})$ dan kalium $(\mathrm{K})$ sangat dibutuhkan tanaman saat proses pembentukan buah serta meningkatkan rasa untuk segala jenis buah. Karena sifat tersebut, sehingga cocopeat dapat digunakan sebagai media yang baik untuk pertumbuhan tanaman hortikultura dan media tanaman hidroponik.

\section{Pengaruh Interaksi, sistem hidroponik dan media tanam}

Hasil analisis sidik ragam menunjukan bahwa pengaruh interaksi sistem NFT dan media tanam cocopeat berpengaruh nyata pada tinggi tanaman umur 5 dan 6 MST, tetapi tidak berpengaruh nyata terhadap jumlah daun, lebar daun dan berat segar tanaman sawi. Dengan sistem NFT dan media tanam cocopeat dapat meningkatkan pertumbuhan tinggi tanaman. Cocopaeat berguna sebagai media menyimpan sementara unsur hara pada media jadi tak mudah tercuci oleh air, dan sangat mudah dilepaskan ketika diperlukan oleh akar tanaman.
Menurut Wuryaningsih (1996), cocopeat mengandung N 0,32\% PO 15\%, KO 31\%, Ca 0,95\%, dan Fe 180 ppm,Mn 80 ppm, Zn 14,1 ppm dan $\mathrm{pH}$ 6,8. Karakteristik lain dari cocopeat adalah ringan, sirkulasi udara tinggi, mengikat air tidak mudah menggumpal. Media cocopeat unsur hara yang dimiliki jumlah yang paling berlimpah adalah unsur kalium $(\mathrm{K})$. Seperti yang telah kita ketahui bahwa kandungan fosfor (P) dan kalium (K) sangat dibutuhkan tanaman saat proses pertumbuhan pembentukan buah serta peningkatan rasa untuk segala jenis buah. Karena sifat tersebut, sehingga cocopeat dapat digunakan sebagai media yang baik untuk pertumbuhan tanaman hortikultura dan media tanam hidroponik, ditambahkan Prihmantoro dan Indriani (2003). Ditambahkan (Karsono,2003) dengan sistem yang baik sehingga dapat membantu meningkatkan pertumbuhan dan hasil dengan sistem NFT tanaman mendapat suplai air, oksigen, dan nutrisi secara periodik, suplai oksigen lebih baik, mempermudah perawatan karena tidak perlu melakukan penyiraman.

\section{KESIMPULAN}

1. Pengaruh sistem hidroponik tertinggi terhadap Jumlah daun, tinggi tanaman, lebar daun, berat segar pada tanaman sawi dicapai oleh perlakuan $S_{2}$ yang berpengaruh sangat nyata terhadap pertumbuhan tanaman sawi.

2. Perlakuan pada media tanam tidak berpengaruh nyata terhadap jumlah daun,tinggi tanaman, lebar daun dan berat segar tanaman pada tanaman sawi hidroponik.

3. Interaksi tidak berpengaruh nyata terhadap jumlah daun, lebar daun, tinggi tanaman, berat segar.

\section{DAFTAR PUSTAKA}

Adiwila, 2010. Faktor-faktor Yang Mempengaruhi Sisi Permintaan dan Sisi Penawaran Sayuran Sawi. Bandung. Penerbit Alumni Bandung.

Arinong, 2008. Panduan Sukses Bertanam Buah dan Sayuran. Klaten : Penerbit Cable Book.

Budiana dan Heriwibowo, 2014. Hidroponik Sayuran Untuk Hobi \& Bisnis. Penebar Swdaya. Jakarta. 
Chadirin, 2007. Manfaat serbuk cocopeat / serbuk sabut Kelapa. Jakarta.

Eko Susilo LITERINDO literatur inspiratif Sumber Gambar,dari berbagai sumber http//www.moissonbeauce.qc.ca

Eko, M. 2007.Budidaya Tanaman Sawi (Brasica juncea) Penebar Swadaya. Jakarta.

Eselon 2014. Dasar Pertanian Hidroponik Sawi. Trubus Swadaya, Jakarta.

Eselon Iv 2014. BPTP Kaltim, Kementerian Kaltim http.prospekbudidayasawi.co.id.

Surtinah .2010.Agronomi Tanaman Budidaya. Trubus Swadaya : Alaf Riau.

Sutinah, 2010. Bertanam Sawi dan Andewi. Kanisius. Yogyakarta.

Haman dan Yeger. 2004. Sistem Drp Irigasi Hidroponik http:/tanamanhidroponik.com eolite-sebagai-media-tanaman-hidroponik.

Diakses pada tanggal 25 Oktober 2013.

Hanafia. K.A 2005. Rancangan Percobaan Teori dan Aplikasi. Cetakan ke-5 Raja Grafindo Persada, Jakarta Utara.

Hendra dan Andoko, 2014.Bertanam Hidroponik Ala Paktanai Hydrofarm PT Agromedia Pustaka.Jakarta Selatan.

Hendra dan Andoko. 2014. Respon Pertumbuhan dan Produksi Sawi (Brassica rafa l) Terhadap Pemberian Urine Kelinci dan Pupuk Guano. Jurnal Online Agroteknologi 1 (3): 646-654.

Hernowo, B. 2010 Panduan Sukses Bertanam Buah dan Sayuran. Klaten : Penerbit Cable Book.

Ihsan, M. 2013. Manfaat Serbuk Cocopeat / Serbuk Sabut Kelapa. Rineka Cipta Jakarta.

Karsono. 2013. Pengaruh Berbagai Media Terhadap Perkecambahan Matoa http:/Semadim.wordpress.com. Diakses pada tanggal 23 September 2013.

Margianto, 2007. Teknologi Budi Daya Tanaman. Agro Media Pustaka. Surabaya.

Prihmatoro dan Indriani 2003. Petunjuk Pemupukan Yang Efektif. Agro Media Pustaka. Depok.

Rahman, 2012. Pengaruh Dosis Pupuk Kompos Enceng Gondok dan Jarak Tanam Terhadap Pertumbuhan dan Hasil Tanaman Sawi (Brassica rapa L). INNOFARM : Jurnal Inovasi Pertanian 12 (12).
Ruaf-asia foundation, 2010. Macam-macam Media Hidroponik Raja Grafindo Persada. Jakarta.

Rukmana, 1995. Budidaya Jenis Sawi. Kanisius. Yogyakarta.

Setiadi,1993. Iklim Ttanaman Sawi. Jenis Sawi Hijau. Surabaya.

Soeseno. 1985. Hidroponik Sayuran Semusim. Penebar Swadaya. Jakarta.

Sutirman 2011. Respon pertumbuhan dan produksi Tanaman sawi (Brassica rapa $L$ ) terhadap pemberian urine kelinci dan pupuk guano. Jurnal online agroteknologi 1 (3): 646654.

Sutiyoso,2015. Hidroponik Sayuran Semusim. Penebar Swadaya. Jakatra.

Wuryaningsih 1996, S. Pertumbuhan Beberapa Setek Melati Pada Tiga Macam Media. Jurnal Penelitian Pertanian. 5(3);50-57. 
J. Agrifarm : Vol. 8 No. 1, Juli 2019 P- ISSN : 2301-9700, E- ISSN : 2540-8892 